\title{
The effects of sauna on tetraplegic and paraplegic subjects
}

\author{
H J Gerner MD ${ }^{1}$ P Engel MD ${ }^{2}$ G C Gass PhD,${ }^{3 *}$ E M Gass MAppSc, ${ }^{3}$ T Hannich \\ MD, ${ }^{1}$ G Feldmann ${ }^{1}$ \\ ${ }^{1}$ Zentrum für Ruckenmarkverletzte, Werner-Wicker Klinik, Bad \\ Wildungen-Reinhardshausen, Germany; ${ }^{2}$ Institut für Arbeitsphysiologie und \\ Rehabilitationsforschung, University of Marburg, Germany; ${ }^{3}$ Rehabilitation Research \\ Centre, Cumberland College of Health Sciences, The University of Sydney, PO Box 170, \\ Lidcombe, NSW 2141, Australia.
}

Six tetraplegic (T) and 4 paraplegic (P) subjects underwent a 20-minute pre sauna phase $\left(30^{\circ} \mathrm{C} \mathrm{DB} ; 65 \% \mathrm{RH}\right)$, and an up to 15 -minute sauna $\left(85^{\circ} \mathrm{C} \mathrm{DB}\right.$; $<10 \% \mathrm{RH})$, followed by a 15 minute post sauna phase $\left(30^{\circ} \mathrm{C} \mathrm{DB} ; 65 \% \mathrm{RH}\right)$. During all phases subjects wore a bathing suit and remained supine on a hospital trolley. Heart rate (HR) and blood pressure (BP) were recorded during all phases. Rectal temperature (Trec) was measured by a probe (AD590) inserted approximately $14 \mathrm{~cm}$ into the rectum. Oral temperature (Toral) also utilising (AD590) circuitry was recorded simultaneously with Trec. Skin temperature (Tsk) (AD590) was measured on the head, chest, right thigh and right calf. Forehead sweat rate (SR) was determined from dew point temperature (Tdp). A catheter was inserted into a dorsal hand or foot vein and venous blood was withdrawn at selected times and analysed for haemoglobin ( $\mathrm{Hb})$ and haematocrit (Hct), and the separated plasma was analysed for glucose (Glu), sodium $\left(\mathrm{Na}^{+}\right)$, potassium $\left(\mathrm{K}^{+}\right)$and chloride $\left(\mathrm{Cl}^{-}\right)$. Venous blood sampled just prior to entering and just prior to leaving the sauna, was analysed for adrenalin (A) and noradrenalin (NA) using high performance liquid chromatography.

For both groups HR rose significantly during the sauna with a significant decline in $\mathrm{HR}$ for the $\mathrm{P}$ group during the post sauna phase. There were no significant changes in systolic BP for either group. A significant decline in diastolic BP was found for the $\mathrm{T}$ group during the post sauna phase. There were no episodes of syncope. Trec for the $\mathrm{T}$ group rose significantly from $37.03 \pm 0.31{ }^{\circ} \mathrm{C}$ at rest to $37.81 \pm 0.32{ }^{\circ} \mathrm{C}$ after 15 minutes of sauna, and Trec continued to rise during the post sauna phase to reach $38.24 \pm 0.61{ }^{\circ} \mathrm{C}$. Trec for the $\mathrm{P}$ group also rose significantly from $37.27 \pm 0.04{ }^{\circ} \mathrm{C}$ at rest to reach $37.75 \pm 0.17^{\circ} \mathrm{C}$ and $37.94 \pm 0.20^{\circ} \mathrm{C}$ at the end of the sauna and post sauna phase respectively. Toral increased significantly for $\mathrm{T}$ and $\mathrm{P}$ groups during sauna to reach $39.50 \pm 0.18^{\circ} \mathrm{C}$ and $39.38 \pm 0.48{ }^{\circ} \mathrm{C}$ respectively. There were significant increases in all Tsk during sauna for both groups.

SR increased significantly during the sauna for the $\mathrm{P}$ group but not for the $\mathrm{T}$ group. The loss in body weight was significantly higher for the $\mathrm{P}$ group $(0.49 \pm 0.17 \mathrm{~kg})$ than the $\mathrm{T}$ group $(0.173 \pm 0.13 \mathrm{~kg})$. The changes in Hb, Hct, Glu, $\mathrm{Na}^{+}, \mathrm{K}^{+}, \mathrm{Cl}^{-}$, and $\mathrm{A}$ were not significant. The NA concentration rose significantly during sauna for the $\mathrm{P}$ group. It would appear that sauna bathing for up to 15 minutes for tetraplegics and paraplegics with a normal body temperature is a safe procedure.

Key words: spinally injured; adrenalin; core temperature; sweat rate; sauna; paraplegia; tetraplegia.

\footnotetext{
*Correspondence.
} 


\section{Introduction}

Paraplegia and tetraplegia results in an impaired thermoregulatory ability, ${ }^{1,2}$ with the extent of this impairment being dependent upon the level and completeness of the spinal cord injury. ${ }^{3}$ Paraplegic and tetraplegic subjects with complete spinal cord lesions exhibit an attenuated or absent sweating response below their spinal lesion, ${ }^{4.5}$ and may demonstrate a raised Tcore at which sweating begins in sensate areas. ${ }^{6}$ These changes in the sweating response, together with the possibility of a reduced blood volume, ${ }^{7}$ a compromised cutaneous blood flow ${ }^{4.8}$ and an attenuated autonomic response $^{9}$ may result in thermal injury and circulatory akinesis when paraplegic or tetraplegic subjects undertake sauna. Typically, the dry Finnish sauna involves whole body exposure to an environment of $85^{\circ} \mathrm{C}$ dry bulb (DB), $5-10 \%$ relative humidity (RH), for up to 15 minutes, followed by a cold water shower or plunge. This procedure of heating and cooling the body may be repeated a number of times during a single visit with the cumulative heat storage, as reflected by increases in core temperature, being dependent upon the number, temperature, and duration of exposures and the effectiveness of the individual's heat dissipation mechanisms. ${ }^{10.11 .12}$

The use of sauna by spinally injured subjects for recreation or as an adjunct therapy in the management of spasticity (HJ Gerner, personal communication) is increasing and yet the physiological responses that occur when spinally injured persons are exposed to sauna remain largely unreported. Küoller and Henning ${ }^{13}$ subjected male and female tetraplegic and able bodied subjects in the sitting position to temperatures of $75{ }^{\circ} \mathrm{C}$ and $30 \% \mathrm{RH}, 80^{\circ} \mathrm{C}$ and $15 \% \mathrm{RH}$ and $80^{\circ} \mathrm{C}$ and $25 \% \mathrm{RH}$ for 16 minutes. Although the heart rate increased for all subjects as the RH increased, there was no measurement of core or skin temperatures in these subjects. Given that typical dry sauna conditions will significantly challenge the thermal homeostasis for the able bodied person, ${ }^{14}$ it seems reasonable to suggest that the spinally injured person, particularly the tetraplegic, could be at greater risk than able bodied subjects of heat related disorders and circulatory akinesis during sauna bathing.

With this in mind the aim of the present experiment was to investigate the physiological effects of a single bout of dry sauna in tetraplegic and in paraplegic subjects.

\section{Methods}

Six tetraplegic and 4 paraplegic subjects volunteered to participate in this study which was approved by the Institutional Ethics Committee. After having all procedures carefully explained and demonstrated during a familiarisation session, each subject was required to give their consent before participating in the experiment. All subjects were patients at the Werner Wicker Klinik, Bad Wildungen, Germany, and their clinical characteristics are presented in Table I. Four tetraplegic subjects were taking medication, 2 were taking an anticholinergic antispasmodic (Dridase), one was taking an antibiotic (bladder infection) and one an antispasmodic drug (Lioresal). No paraplegic subject was taking any anticholinergic medication. On the day following the familiarisation session, each subject visited the experimental area which consisted of a preparation site immediately adjacent to a large wooden sauna. The environmental conditons for the preparation site and in the sauna were $30^{\circ} \mathrm{C}(\mathrm{DB})$, $65 \% \mathrm{RH}$ and $85^{\circ} \mathrm{C} \mathrm{DB},<10 \% \mathrm{RH}$, respectively. The experiment was divided into pre sauna, sauna and post sauna phases and during all phases of the experiment each subject wore a bathing suit and remained supine on a hospital trolley. The sauna was heated for 90 minutes prior to the first subject entering the sauna, and all temperature and RH measurements were taken at chest level with the patient supine on the hospital trolley.

In the preparation area, subjects were weighed to the nearest $10 \mathrm{gm}$ on a stretcher suspended from a divided scale, with appropriate adjustments made for the weight of the stretcher, sheet and pillow (body weight 1). Three electrocardiographic (ECG) electrodes were attached in the CM5 position to monitor heart rate (HR) throughout all 
Table I Clinical and physical characteristics of subjects

\begin{tabular}{|c|c|c|c|c|c|}
\hline No. & Sex & $\begin{array}{l}\text { Age } \\
\mathrm{y} / \mathrm{m}\end{array}$ & Lesion level & Cause & $\begin{array}{l}\text { Time since } \\
\text { injury }\end{array}$ \\
\hline 1 & $\mathrm{~F}$ & $41 / 2$ & $\begin{array}{l}\text { Motoric incomplete, func- } \\
\text { tionally incomplete below } \\
\text { C4/5 }\end{array}$ & $\begin{array}{l}\text { Subluxation/ } \\
\text { compression fracture } \\
\text { C4/5 (MVA) }\end{array}$ & 12 month \\
\hline 2 & M & $23 / 1$ & $\begin{array}{l}\text { Complete tetraplegia below } \\
\text { C5 }\end{array}$ & $\begin{array}{l}\text { Compression frac- } \\
\text { ture subluxation C5 } \\
\text { (MVA) }\end{array}$ & 10 months \\
\hline 3 & M & $33 / 5$ & $\begin{array}{l}\text { Complete tetraplegia below } \\
\text { C5 }\end{array}$ & MVA & 16 years \\
\hline 4 & M & $36 / 6$ & $\begin{array}{l}\text { Motoric complete below C6. } \\
\text { Sensible complete below } \mathrm{T} 12\end{array}$ & $\begin{array}{l}\text { C5/6 subluxation } \\
\text { (swimming) }\end{array}$ & 6 weeks \\
\hline 5 & $\mathrm{~F}$ & $21 / 5$ & $\begin{array}{l}\text { Complete tetraplegia below } \\
\text { C6 }\end{array}$ & $\begin{array}{l}\text { C6 compression } \\
\text { fracture subluxaton } \\
\text { (MVA) }\end{array}$ & 6 weeks \\
\hline 6 & M & $41 / 5$ & $\begin{array}{l}\text { Complete tetraplegia below } \\
\text { C7 }\end{array}$ & $\begin{array}{l}\text { C5 compression } \\
\text { fracture subluxation } \\
\text { (swimming) }\end{array}$ & 10 months \\
\hline 7 & $\mathrm{~F}$ & $24 / 5$ & $\begin{array}{l}\text { Beginning incomplete (func- } \\
\text { tionally complete) paraplegia } \\
\text { below T10 }\end{array}$ & Scoliosis operation & 3 months \\
\hline 8 & M & $49 / 1$ & $\begin{array}{l}\text { Complete paraplegia below } \\
\mathrm{T} 4\end{array}$ & $\begin{array}{l}\text { Astrocytoma } \\
\text { operation }\end{array}$ & 5 years \\
\hline 9 & M & $23 / 0$ & $\begin{array}{l}\text { Complete paraplegia below } \\
\text { T8 }\end{array}$ & $\begin{array}{l}\text { Compression by } \\
\text { spinal angioma }\end{array}$ & $\begin{array}{l}\text { Detected } 2 \text { years } \\
\text { previously }\end{array}$ \\
\hline 10 & M & $40 / 3$ & $\begin{array}{l}\text { Complete paraplegia below } \\
\text { T9 }\end{array}$ & $\begin{array}{l}\text { Compression frac- } \\
\text { ture T9 (MVA) }\end{array}$ & 18 years \\
\hline
\end{tabular}

phases of the experiment. A thin, flexible and calibrated temperature probe utilising the integrated circuit principle (AD590) was inserted approximately $14 \mathrm{~cm}$ into the rectum by a nurse or medical practitioner. All temperature probes had been previously calibrated against a precision thermometer $\left(0.05^{\circ} \mathrm{C}\right)$ in a water bath. Great care was taken to position the rectal probe so as to avoid any pressure points. Skin temperature probes, also utilising AD590 circuitry, were attached to the head, chest, anterior aspect of the right thigh and anterolateral aspect of the right calf. The rectal and skin temperatures were monitored throughout the experiment and recorded every 2 minutes. A sweat capsule utilising the principle of dew point hygrometry as described by Graichen et al ${ }^{15}$ was attached securely to the forehead of each subject to detect the onset of sweating and for the subsequent calculation of sweat rate. Oral temperature also using AD590 circuitry was measured simul- taneously with rectal temperature, with each subject being requested to place the small temperature probe under their tongue and to keep their mouth closed during all phases of the experiment. An indwelling catheter was inserted into either a dorsal hand or foot vein using sterile techniques and patency was maintained by sterilised heparinised saline.

Once all the equipment was attached and final calibration procedures completed, each subject began a 20-minute pre sauna phase. Both the pre and post sauna phases were conducted in the preparation area.

\section{Pre sauna phase}

A $10 \mathrm{ml}$ venous blood sample was withdrawn 15 minutes before entering the sauna $(-15 \mathrm{~min})$ and a further $10 \mathrm{ml}$ sample was taken just prior to entering the sauna $(0 \mathrm{~min})$. Blood pressure was recorded via auscultation from the upper right arm at the 
beginning of the pre sauna phase and 5 minutes before entering the sauna. Systolic and diastolic blood pressures were recorded at the first and fifth Korotkow sounds respectively. Dew point temperature (Tdp) (from sweat capsule), heart rate (HR), skin (Tsk), oral (Toral) and rectal (Trec) temperatures were monitored continuously throughout and recorded 10,5 and 1 minute before entering the sauna.

\section{Sauna phase}

The supine subject was wheeled into the sauna and positioned approximately $1.5 \mathrm{~m}$ from the sauna heater. For all subjects, the positioning of the trolley inside the sauna was standardised. The sauna phase lasted for 15 minutes, or until the subject requested removal or reported nausea or dizziness, Trec reached $39.0^{\circ} \mathrm{C}$, or ECG abnormalities were observed. Blood pressure and heart rate were recorded every 5 minutes, Tsk for 4 sites was recorded every 3 minutes, Toral and Trec every minute and Tdp recorded every 20 seconds. Just prior to the subject being removed from the sauna $(15 \mathrm{~min})$ a further $10 \mathrm{ml}$ of venous blood was withdrawn, then the subject was wheeled from the sauna to the preparation area for the post sauna phase.

\section{Post sauna phase}

The post sauna recovering period lasted 15 minutes, during which time blood pressure and heart rate was recorded at 5-minute intervals, Tsk every 3 minutes, Toral and Trec recorded every 1 minute and Tdp was recorded every 20 seconds. A further $10 \mathrm{ml}$ venous blood sample was withdrawn just prior to the end of the post sauna phase $(+15 \mathrm{~min})$. At the end of the post sauna phase each subject was wiped dry, all recording equipment was removed and the subject was reweighed (body weight 2). Where possible the second body weight was obtained 20 minutes after the conclusion of the post sauna phase. After the second weighing, each subject was offered a drink of water, was showered and prepared for their return to the ward. Upon returning to the ward careful observation of each subject was maintained for a further one to 4 hours.
The venous blood taken at each collection period was analysed for haemoglobin $(\mathrm{Hb})$, and haematocrit (Hct). The separated plasma was analysed for glucose (Glu), sodium $\left(\mathrm{Na}^{+}\right)$, potassium $\left(\mathrm{K}^{+}\right)$, and chloride $\left(\mathrm{Cl}^{-}\right)$. In addition, the venous blood sampled just prior to entering the sauna and just prior to leaving it, was analysed for adrenalin (A) and noradrenalin (NA) by high performance liquid chromatography (HPLC).

\section{Statistical analysis}

Means and standard errors were calculated for all dependent variables. The paraplegic and tetraplegic data were analysed separately and no statistical comparisons were made between groups. A multivariate analysis of variance with repeated measures (MANOVA) was used to determine which means among conditions (pre sauna, sauna, post sauna) and over time (repeated measures) were significantly different. A paired t-test was used to test for significant changes in body weight. For all statistical analyses the 0.05 probability level was adopted and all analyses were performed using a microcomputer-based statistical programme (SYSTAT: The System for Statistics V4.0).

\section{Results}

The heart rate responses pre, during and post sauna for the tetraplegic (T) and paraplegic $(\mathrm{P})$ groups are presented in

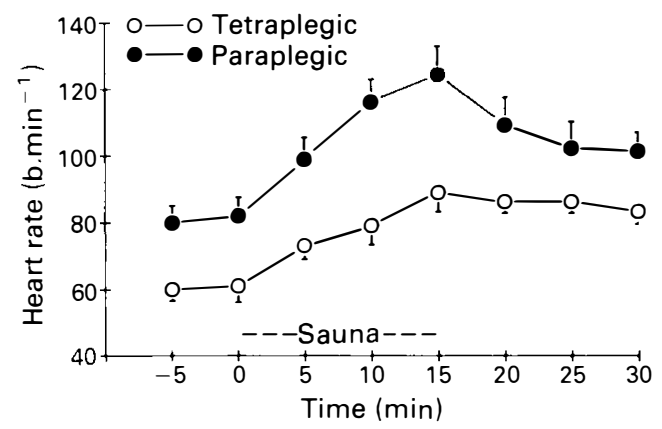

Figure 1 Heart rate response $(\overline{\mathrm{X}} \pm \mathrm{SE})$ pre, during and post sauna for tetraplegic $(\mathrm{T})$ and paraplegic $(\mathrm{P})$ groups. 
Figure 1 . The resting heart rate $(0 \mathrm{~min})$ for the $\mathrm{T}$ group was $61 \pm 5 \mathrm{~b}$. $\mathrm{min}^{-1}$ rising significantly to $79 \pm 6$ and $89 \pm 8$ b. $\mathrm{min}^{-1}$ after 10 and 15 minutes of sauna, respectively. There was no significant decline in HR up to 15 minutes of post-sauna recovery for the $T$ group.

The HR at rest for the $\mathrm{P}$ group was $82 \pm 6$ b. $\min ^{-1}$, rising significantly during sauna exposures to $99 \pm 7,116 \pm 7$ and $124 \pm 9$ b.min ${ }^{-1}$ after 5, 10 and 15 minutes respectively. Following the sauna exposure the post-sauna recovering heart rate declined significantly during each 5 minute period to $101 \pm 6 \mathrm{~b} \cdot \mathrm{min}^{-1}$ after 15 minutes.

Blood pressure changes during all phases of the experiment for both the $\mathrm{T}$ and $\mathrm{P}$ groups are presented in Figure 2. Although there were no significant changes in diastolic blood pressure (DBP) for the $\mathrm{T}$ group during sauna exposure, the DBP at +5 and $+10 \mathrm{~min}$ of the post-sauna phase were significantly lower than initial resting values. There were no significant changes in systolic blood pressure (SBP) during any phase of the experiment for the T group.

There were no significant changes in either SBP or DBP for the P group during any phase of the experiment.

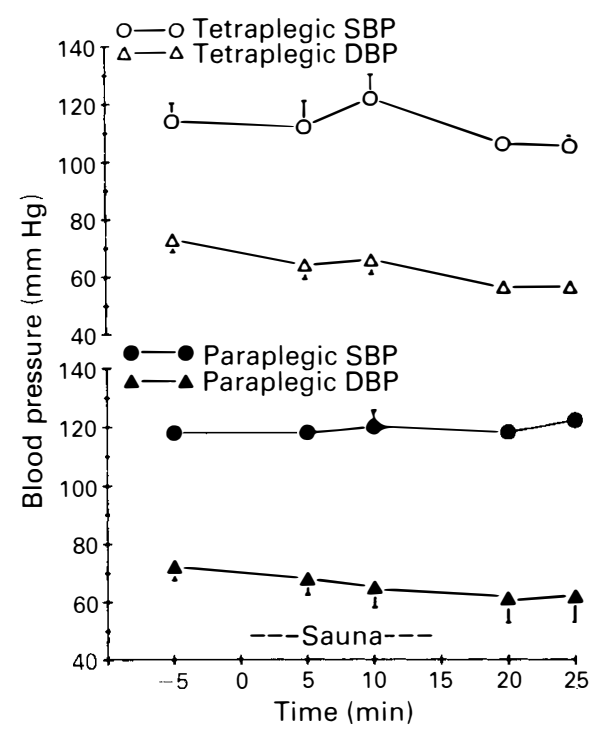

Figure 2 Blood pressure changes $(\overline{\mathrm{X}} \pm \mathrm{SE})$ pre, during and post sauna for tetraplegic (T) and paraplegic $(\mathrm{P})$ groups.
Trec and Toral changes for both groups are illustrated in Figure 3. The resting Trec for the $\mathrm{T}$ group was $37.03 \pm 0.31{ }^{\circ} \mathrm{C}$ which rose significantly to $37.81 \pm 0.32^{\circ} \mathrm{C}$ after 15 minutes of sauna exposure. During the post sauna phase the Trec continued to rise significantly reaching $38.24 \pm 0.61^{\circ} \mathrm{C}$ after 15 minutes. The Trec at 5,10 and 15 minutes post sauna was significantly higher than at all other time periods before and during sauna except the 13 and 15 minutes of the sauna phase.

For the $\mathrm{P}$ group, the Trec also rose significantly from $37.27 \pm 0.04{ }^{\circ} \mathrm{C}$ at rest to $37.75 \pm 0.17^{\circ} \mathrm{C}$ after 15 minutes of sauna. Trec continued to rise during the post sauna recovery, reaching $37.94 \pm 0.20^{\circ} \mathrm{C}$ after 10 minutes, and remaining at this level until the end of the post sauna period. At 5, 10 and 15 minutes of the post sauna phase the Trec was significantly higher than pre sauna and during the first 10 minutes of sauna. Oral temperature for the $\mathrm{T}$ group rose significantly from $36.80 \pm 0.25^{\circ} \mathrm{C}$ at rest to reach $39.50 \pm 0.18^{\circ} \mathrm{C}$ after 15 minutes of sauna and then declined significantly during the post sauna recovery to be $38.30 \pm$ $0.18{ }^{\circ} \mathrm{C}$ after 15 minutes. In the $\mathrm{P}$ group Toral at rest was $36.85 \pm 0.10^{\circ} \mathrm{C}$ rising

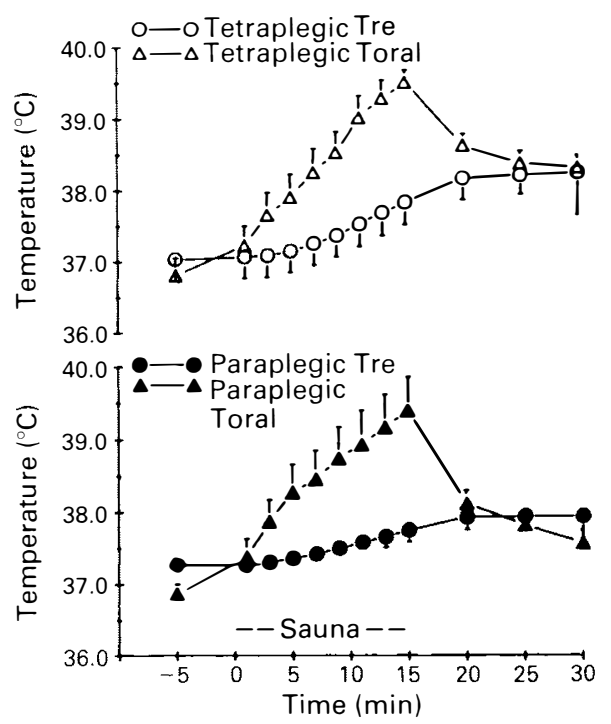

Figure 3 Rectal (Trec) and oral (Toral) temperatures $(\bar{X} \pm S E)$ pre, during and post sauna for tetraplegic $(\mathrm{T})$ and paraplegic $(\mathrm{P})$ groups. 
significantly to $39.38 \pm 0.48^{\circ} \mathrm{C}$ after 15 minutes of sauna exposure. There was a significant decline in Toral after removal from sauna to $37.56 \pm 0.19^{\circ} \mathrm{C}$ at the end of the post-sauna phase $(+15 \mathrm{~min})$.

The differene between Toral and Trec $(\Delta$ Tor-rec) for each group became significantly greater with the duration of the sauna exposure resulting in a $\Delta$ Tor-rec after 15 minutes of sauna of $1.68 \pm 0.19^{\circ} \mathrm{C}$ and $1.63 \pm 0.36{ }^{\circ} \mathrm{C}$ for the $\mathrm{T}$ and $\mathrm{P}$ groups respectively. The changes in skin temperature recorded at 4 sites (head, chest, thigh and calf) for both groups ( $T$ and $\mathrm{P}$ ) are shown in Figure 4. For the $\mathrm{T}$ and $\mathrm{P}$ groups each of the skin temperatures was significantly higher during the sauna phase than at rest. During the post sauna recovery phase each of the skin temperatures for both groups ( $\mathrm{T}$ and $\mathrm{P}$ ) declined significantly.

The sweat rate (SR) mg. $\mathrm{min}^{-1} \cdot \mathrm{cm}^{-2}$, for both groups at rest and during $(5,10$ and 15 minutes) sauna is presented in Figure 5. Although the SR for the T group increased from $0.28 \pm 0.09 \mathrm{mg} \cdot \mathrm{min}^{-1} \cdot \mathrm{cm}^{-2}$ at 5 minutes of sauna to $1.13 \pm 0.37 \mathrm{mg}$. $\min ^{-1} \cdot \mathrm{cm}^{-2}$ at 15 minutes of the sauna, this

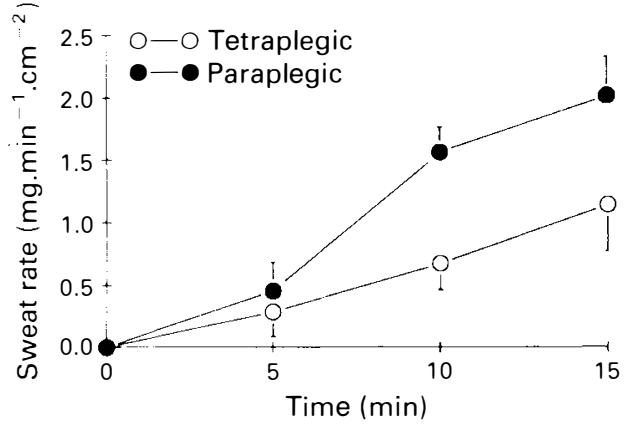

Figure 5 Forehead sweat rate $(\bar{X} \pm S E)$ at rest and during sauna in tetraplegic $(\mathrm{T})$ and paraplegia $(\mathrm{P})$ groups.

increase in SR was not significant. For the P group, $\mathrm{SR}$ rose significantly from $0.45 \pm 0.23 \mathrm{mg} \cdot \mathrm{min}^{-1} \cdot \mathrm{cm}^{-2}$ at 5 minutes to $1.55 \pm 0.06$, and $2.0 \pm 0.31 \mathrm{mg} . \mathrm{min}^{-1} . \mathrm{cm}^{-2}$ after 10 and 15 minutes respectively. All subjects in the $\mathrm{P}$ group and all but one subject (No 5) in the $\mathrm{T}$ group showed forehead sweating during the sauna.

The pre sauna body weight for the $\mathrm{T}$ and $P$ groups was $76.75 \pm 6.82$ and $69.02 \pm$
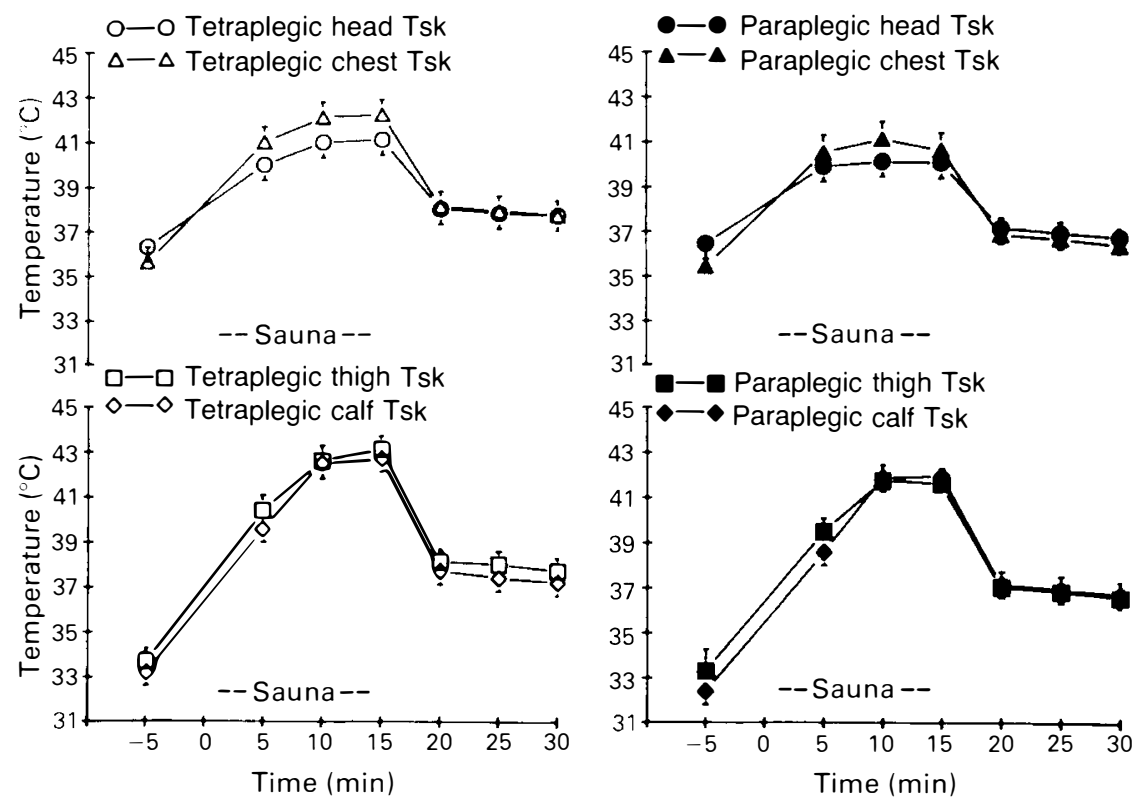

Figure 4 Head, chest, thigh and calf skin temperatures $(\bar{X} \pm S E)$ pre, during and post sauna for tetraplegic $(\mathrm{T})$ and paraplegic $(\mathrm{P})$ groups. 
$5.8 \mathrm{~kg}$ respectively and the exposure to sauna resulted in respective losses of body weight $(\Delta \mathrm{BW})$ of $0.173 \pm 0.13$ and $0.49 \pm 0.17 \mathrm{~kg}$. The $\Delta \mathrm{BW}$ for both groups was significant.

For the tetraplegic and paraplegic groups no significant changes were observed in the plasma sodium, potassium, chloride and glucose concentrations. The changes in haemoglobin and haematocrit concentrations for both groups were also not significant.

The adrenalin (A) and noradrenalin (NA) concentrations just prior to entering the sauna $(0 \mathrm{~min})$ and just before leaving the sauna $(15 \mathrm{~min})$ are shown in Figure 6. For the $\mathrm{P}$ group, the NA concentration just prior to entering the sauna was $415.5 \pm$ $53.4 \mathrm{pg} \cdot \mathrm{ml}^{-1}$ rising significantly to $598.2 \pm$ $48.4 \mathrm{pg} \cdot \mathrm{ml}^{-1}$ just before leaving the sauna. The changes in NA concentration for the T group over the same time period were not significant. The A concentration for both groups over the same time period did not change significantly.
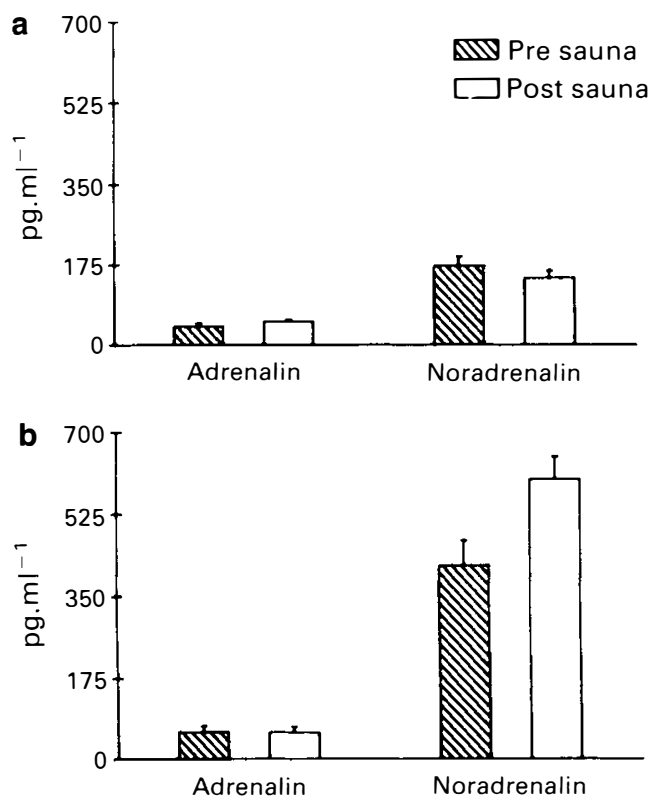

Figure 6 Adrenalin and noradrenalin concentration $(\bar{X} \pm S E)$ pre and at the end of sauna in (a) tetraplegic (T) and (b) paraplegic (P) groups.

\section{Discussion}

The present study investigated the effects of a single 15 -minute exposure to dry sauna $\left(85^{\circ} \mathrm{C},<10 \% \mathrm{RH}\right)$ in a group of tetraplegic and in a group of paraplegic subjects. Since the 2 groups of subjects could be expected to demonstrate differences in sensory, motor and autonomic responses arising from dissimilar lesion levels, the discussion has focused upon each group's responses separately. Some intergroup comparisons have been drawn in an attempt to highlight the differences between paraplegic and tetraplegic subjects when exposed to sauna.

Heart rate increased linearly with duration of sauna exposure in both $\mathrm{T}$ and $\mathrm{P}$ groups. This pattern of response was consistent with results reported for able bodied subjects $^{12}$ and with the results of other tetraplegic subjects exposed to sauna. ${ }^{13}$ In the present study the pre sauna heart rate was lower in the $T$ group than in the $P$ group, and remained attenuated throughout the sauna exposure. This attentuated HR response in tetraplegic subjects has been shown by others ${ }^{13}$ and is consistent with injury to the cervical area of the spinal cord. ${ }^{16}$

The systolic and diastolic blood pressure changes in both the $\mathrm{T}$ and $\mathrm{P}$ groups were consistent with those measured on other paraplegic and tetraplegic subjects exposed to $15 \mathrm{~min}$ of sauna ( $\mathrm{P}$ Engel, personal communication, 1990). Because of the reported variability in the blood pressure response during sauna for able bodied individuals $^{17,18}$ all subjects in the present study were in the supine position during sauna. There were no significant changes in systolic or diastolic blood pressures during sauna, but there was a significant decline in diastolic blood pressure in the $\mathrm{T}$ group during the post sauna phase. There were no episodes of syncope in either group, and it would appear that in both $\mathrm{T}$ and $\mathrm{P}$ groups the supine position may be advantageous in maximising venous return and thereby lessening the importance of heart rate in maintaining cardiac output.

In this study sweat rate was measured from the forehead because of the high rate of sweat production in this area in compari- 
son with other sites, ${ }^{19}$ and because the sweat capsule could be easily and firmly attached for all subjects. The SR after 15 minutes of sauna exposure in the $\mathrm{P}$ group of the present study $\quad\left(2.00 \pm 0.31 \mathrm{mg} \cdot \mathrm{min}^{-1} . \mathrm{cm}^{-2}\right) \quad$ was higher than that recorded by others $(G$ Brengelmann, personal communication) in a group of paraplegic men heated in a water perfused suit. The higher sweat rate in the present group of paraplegic subjects was likely due to the higher mean skin temperatures. This reasoning is wholly consistent with the findings of others ${ }^{20}$ who have observed that mean skin temperature is a significant afferent stimulus in the central drive to sweat during passive heating.

Although the increase in SR in the tetraplegic subjects during sauna exposure, was not statistically significant, the possible physiological significance of the SR:Trec relationship should not be overlooked. Subject No 4 with a high SR (1.3 mg.min $\left.{ }^{-1} . \mathrm{cm}^{-2}\right)$ showed a $\Delta$ Trec of $0.34^{\circ} \mathrm{C}$, whereas subject No 5 with minimal forehead sweating $\left(<0.1 \mathrm{mg} \cdot \mathrm{min}^{-1} \cdot \mathrm{cm}^{-2}\right)$ demonstrated a $\Delta$ Trec of $1.31^{\circ} \mathrm{C}$. Subject No 6 also showed minimal forehead sweating; however, the $\Delta$ Trec by the end of the sauna phase was only $0.4^{\circ} \mathrm{C}$. Interestingly the initial Trec for subject No 6 was $36.19^{\circ} \mathrm{C}$ rising to $36.59{ }^{\circ} \mathrm{C}$ after 15 minutes of sauna. Nothwithstanding the loss of sympathetic activity, it is unlikely that this temperature $\left(36.59^{\circ} \mathrm{C}\right)$ was sufficient to provoke the onset of sweating. The relationship between the onset of sweating and oesophageal temperature has been well established for able bodied subjects ${ }^{21}$ and recent unpublished studies investigating this relationship in paraplegic and tetraplegic subjects (G Brengelmann, personal communication) would suggest that it was unlikely that subject No 6 had reached the threshold temperature for the onset of sweating.

The sweating response in 2 tetraplegic subjects Nos 1,5 may have been confounded by the administration of anticholinergic medication (Dridase). Indeed the essentially absent sweating response in subject No 5, could have been due to the anticholinergic medication, rather than the lack of central drive to the sweat gland or the failure to reach a threshold temperature.
Interestingly, however, in subject No 1 who was taking the same amount of Dridase $(4 \times 1 / 2 \mathrm{tab})$ as subject No 5, a SR $>$ $2.5 \mathrm{mg} \cdot \mathrm{min}^{-1} \cdot \mathrm{cm}^{-2}$ and Trec of $37.84^{\circ} \mathrm{C}$ was recorded at the end of sauna.

While most subjects showed some sweating response, the contribution of sweating to the overall heat dissipation during sauna has to be balanced by the area of wet skin and the environmental conditions in the sauna. The environmental conditions that existed in the sauna $\left(85^{\circ} \mathrm{C} \mathrm{DB},<10 \% \mathrm{RH}\right)$ in the present study were not likely to be conducive to increasing the rate of sweat evaporation. With a reduction in total sweat production, and rate of evaporation of sweat, the rate of body heat storage could be expected to increase, thereby accounting for the increased $\Delta$ Trec in both groups of subjects.

The $\Delta \mathrm{BW}$ in the $\mathrm{P}$ group $(0.49 \pm 0.17 \mathrm{~kg})$ but not the $T$ group $(0.173 \pm 0.13 \mathrm{~kg})$ is consistent with $\Delta \mathrm{BW}$ values reported for able bodied males ${ }^{12,22,23}$ exposed to sauna for 15-20 minutes. If $\Delta \mathrm{BW}$ reflects sweat loss, then in the present study the $\mathrm{P}$ group had a higher sweat rate. This is in agreement with the forehead sweat rate calculated from the measurement of dew point temperature. The disparity between the $\mathrm{P}$ and $\mathrm{T}$ groups in the rate and area of sweating is an expected consequence of the level of spinal cord lesion. ${ }^{9}$

In this study it was originally planned to record simultaneously oesophageal and rectal temperatures, but the difficulty of inserting the temperature probe into the oesophagus and the potential discomfort for the subject of large amounts of recording equipment during the sauna, made the use of an oesophageal probe impractical. Trec was used, therefore, to estimate core temperature. The validity of Trec as an estimate of core temperature at rest and during lower body exercise has been demonstrated elsewhere. ${ }^{24}$ The rise in Trec $\left(0.68 \pm 0.11^{\circ} \mathrm{C}\right)$ during the sauna phase for the $\mathrm{P}$ group is consistent with results from other paraplegic subjects ( $\mathrm{P}$ Engel, personal communication). In the $\mathrm{P}$ group, Trec continued to rise during the initial stage of the post sauna recovery, but 5 minutes after being removed from the sauna to an environment of $30^{\circ} \mathrm{DB}$ $25^{\circ} \mathrm{WB}$, Trec had plateaued. The Trec 
changes in tetraplegic subjects during sauna are previously unreported. As a result of sauna the Trec in the $\mathrm{T}$ group rose by $1.22 \pm 0.18{ }^{\circ} \mathrm{C}$. The higher rise in Trec in the $\mathrm{T}$ group may be due to their reduced sweating response and their inability to effectively redistribute splanchnic and peripheral blood flows.

In the present study oral temperature was measured in an attempt to provide a simple and non invasive method for estimating the rate heat storage during sauna. The respective differences between Trec and Toral during the pre sauna phase for the $\mathrm{P}$ and $\mathrm{T}$ groups was $0.22 \pm 0.09$ and $0.24 \pm 0.02{ }^{\circ} \mathrm{C}$; and is larger than that reported for able bodied subjects. ${ }^{24} \mathrm{By}$ the end of the sauna the Toral was $1.63 \pm 0.36$ and $1.68 \pm$ $0.19^{\circ} \mathrm{C}$ higher than the Trec for the $\mathrm{P}$ and $\mathrm{T}$ groups respectively, and confirms the effect of high ambient temperature upon Toral measurements. ${ }^{25}$ This discrepancy between Toral and Trec raises serious doubt about the validity of Toral to estimate core temperature under high environmental temperature.

Changes in adrenalin and noradrenalin concentration in spinally injured subjects during sauna have not been previously reported. The majority of evidence from studies using able bodied subjects suggests that sauna exposure is more likely to increase the concentration of noradrenalin than adrenalin. ${ }^{17,23,26}$ In the present study, only NA in the P group increased significantly during sauna. The lack of increase in NA concentration in the $T$ group during sauna should not be surprising given that the preganglionic fibres of the sympathetic nervous system begin their exit at the first thoracic vertebrae. The lower plasma NA concentration in the $\mathrm{T}$ group at rest and during sauna, is probably reflecting an attenuated sympathetic nerve activity. ${ }^{27}$

There were no significant changes in $\mathrm{Na}^{+}$, $\mathrm{K}^{+}, \mathrm{Cl}^{-}$concentrations for the $\mathrm{P}$ and $\mathrm{T}$ groups throughout the 3 phases of the experiment. Although the changes in $\mathrm{Na}^{+}$, $\mathrm{K}^{+}, \mathrm{Cl}^{-}$are unreported for $\mathrm{P}$ and $\mathrm{T}$ subjects during sauna, the present results are consistent with some results from able bodied subjects $^{23.28}$ exposed to sauna. The changes in plasma glucose concentration were not significant for either group.

\section{Conclusions}

The present study found that when paraplegic and tetraplegic subjects are exposed to dry sauna $\left(85^{\circ} \mathrm{C} \mathrm{DB},<10 \% \mathrm{RH}\right)$ for 15 minutes there were significant increases in rectal temperature, skin temperature, and heart rate for both groups. For the $\mathrm{P}$ group significant increases were also found for sweat rate and plasma noradrenalin. It would appear that paraplegics and tetraplegics with a normal resting body temperature are at minimal risk during a 15-minute dry sauna.

\section{Acknowledgement}

The authors wish to thank all the subjects who participated and the nursing staff at Werner Wicker Klinik.

\section{References}

1 Guttman L, Silver J, Wyndham CH (1958) Thermoregulation in spinal man. J Physiol 142: 406-419.

2 Pledger HG (1962) Disorders of temperature regulation in acute traumatic tetraplegia. J Bone Joint Surg 44: 110-112.

3 Cooper KE, Ferres HM, Guttmann L (1957) Vasomotor responses in the foot to raising body temperature in the paraplegic patient. J Physiol 136: 547-555.

4 Freund PR, Brengelmann GL, Rowell LB, Halar E (1984) Attenuated skin blood flow response to hyperthermia in paraplegic men. J Appl Physiol 56: 1104-1109.

5 Tam HS, Darling RC, Chen HY, Downey JA (1978) The dead zone of thermoregulation in normal and paraplegic man. Can J Physiol Pharmacol 56: 976-983.

6 Huckaba CE, Frewin DB, Downey JA, Tam HS, Darling RC, Chen HY (1976) Sweating responses of normal, paraplegic and anhidrotic subjects. Arch Phys Med Rehabil 57: 268-274.

7 Knutsson E, Lewenhaupt-Olsson E, Thorsen M (1973) Physical work capacity and physical conditioning in paraplegic patients. Paraplegia 11: 205-216.

8 Normell LA (1974) Distribution of impaired cutaneous vasomotor and sudomotor function in paraplegic man. Scand J Clin Lab Invest (Suppl 33) 138: 25-41. 
9 Piepmeier JM, Lehmann KB (1985) Cardiovascular instability following acute cervical spinal cord trauma. Cent Nerv Syst Trauma 2: 153-160.

10 Kukkonen-Harjula K, Pekka O, Laustiola K, et al (1989) Haemodynamic and hormonal responses to heat exposure in a Finnish sauna bath. Eur J Appl Physiol 58: 543-550.

11 Kauppinen K (1989) Sauna, shower and ice water immersion. Physiological responses to brief exposures to heat, cool, and cold. Part I. Body fluid balance. Arct Med Res 48: 55-63.

12 Sohar E, Shoenfeld Y, Shapiro Y, Ohry A, Cabili S (1976) Effects of exposure to Finnish sauna. Israel J Med Sci 12: $1275-1282$.

13 Kn̈oller H, Henning K (1977) Vertraglichkeit und Auswirkungen des Saunabades bei tetraplegikern. Sonderdruck Z Krgym 29: 599-603.

14 Kauppinen K, Vuori I (1986) Man in the sauna. Ann Clin Res 18: 173-185.

15 Graichen H, Rascati R, Gonzales RR (1982) Automatic dew point temperature sensor. J Appl Physiol 52: $1658-1666$.

16 Lehmann KG, Lane JG, Piepmeier JM et al (1987) Cardiovascular abnormalities accompanying acute spinal cord injury in humans: incidence, time course and severity. J Amer Coll Cardiol 10: 46-52.

17 Vuori I (1988) Sauna bather's circulation. Ann Clin Res 20: 249-256.

18 Lehtmets ML (1957) The sauna bath. History, development and physiological effects. Int Rev Phys Med Rehabil February: 21-64.

19 Downey JA, Huckaba CE, Kelley PS, Tam HS, Darling RC, Chen HY (1976) Sweating responses to central and peripheral heating in spinal man. J Appl Physiol 40: 701-706.

20 Gisolfi CV, Wenger CB (1984) Temperature regulation during exercise: old concepts, new ideas. Exerc Sport Sci Rev 12: 339-372.

21 Nadel ER, Mitchell JW, Saltin B, Stolwijk JAJ (1971) Peripheral modifications to the central drive for sweating. J Appl Physiol 31: 828-833.

22 Kauppinen K (1989) Sauna, shower, and ice water immersion. Physiological responses to brief exposures to heat, cool and cold. Part III. Body temperatures. Arct Med Res 48: 75-86.

23 Taggart P, Parkinson P, Carruthers M (1972) Cardiac responses to thermal, physical and emotional stress. Br Med J 3: 71-76.

24 Mairiaux PH, Sagot JC, Candas V (1983) Oral temperature as an index of core temperature during heat transients. Eur J Appl Physiol 50: 331-341.

25 Bardswell ND, Chapman JE (1911) Some observations upon the deep temperature of the human body at rest and after muscular exertion. Br Med $J$ : 1106-1110.

26 Hussi E. Sönck T, Pösö H, Remes J, Lisalo A, Jänne J (1977) Plasma catecholamines in Finnish sauna. Ann Clin Res 9: 301-304.

27 Rowell LB (1983) Cardiovascular aspects of human thermoregulation. Circ Res 52: 367-379.

28 Caldwell JE, Ahonen E, Nousiainen U (1984) Differential effects of sauna-, diuretic-, and exercise-induced hypohydration. J Appl Physiol 57: 1018-1023. 